\title{
The Relationship Between Walk Distance and Muscle Strength, Muscle Pain in Visually Disabled People
}

\author{
Betül Akyol \\ Correspondence: Inonu University Faculty of Sport Sciences Department of Exercise and Sports Education in \\ Disabilities, Turkey.
}

Received: February 25, 2018

Accepted: March 7, 2018

Online Published: March 16, 2018

doi:10.11114/jets.v6i4.3043

URL: https://doi.org/10.11114/jets.v6i4.3043

\begin{abstract}
The purpose of this study is to examine the relationship between six-minute walk test and muscle pain, muscle strength in visually disabled people. The study includes 50 visually disabled people, aged between 17, $21 \pm 5,3$. Participants were classified into three categories according to their degree of vision (B1, B2, B3). All participants were administered to six-minute walk test, muscle test and muscle pain threshold test.

In B2 and B3 group there is significant moderate correlation between the walk distance and muscles. There were significant differences in pain threshold of quadriceps, pain threshold of hamstring and pain threshold of tibialis anterior among the groups. The data were evaluated using IBM SPSS Statistics 23.0 package software, and the level of significance was taken as $\mathrm{p}<0.005$.

When the visually disabled people were classified according to their visual degree, it was noticed that visual area is important while walking. Muscle power is thought to be effective in walking ability. The muscles of the legs, backs and buttocks act as they walk and allow them to stay in balance. In addition to the muscular strength, people with muscle pain do not want to continue walking because they are feeling pain in their muscles as they walk.

As a result, if we want to increase walking distance, which is an important part of daily life activities of visually impaired individuals, an exercise program should be organized to strengthen muscle groups that are effective in walking and to rehabilitate painful muscles.
\end{abstract}

Keywords: visually disabled people, walk distance, muscle strength

\section{Introduction}

Gait is a dynamic balance condition which comprises a system in which the central nervous system continuously processes sensory input received from every reglion of the body during walking, achieving efficient and appropriate locomotor activity. As long the central nervous system is maintained over the base of support, gait is stable (Beauchet, Launay, Fantino, Allali \& Annweiler 2015; Nakamura, 1997).

To maintain postural stability while walking, an individual is therefore required to actively control the movements of its center of gravity. Several physiological sensory and motor subsystems contribute to the dynamic postural control with muscle strength, lower limb proprioception, vision and cognition. Gait is effected from the impairments in sensorimotor subsystems (muscle strength, lower-limb proprioception and distance vision (Beauchet, Launay, Fantino, Allali \& Annweiler 2015).

In particular, the two elements of orientation, corresponding to the sensory system and mobility corresponding to the motor system, must function smoothly for visually impaired persons to walk safely and efficiently. In walking the role of the visual system is to perceive feedback input regarding changes and to increase the adaptation of the posture to the walking environment. It has been theorized that visually impaired persons who are unable to make full use of visual input achieve appropriate gait control during walking by utilizing a combination of somatosensory, auditory, or other non-visual sensory input (Nakamura, 1997).

The visually impaired people have shown shorter stride length, more backward trunk position compared with a normally sighted people (Hallemans, Ortibus, Meire \& Aerts, 2010). Because of this reason when visually disabled people walk on a way, they can walk shorter distance than sighted people.

Nonetheless muscle strength is an important, skill-related component of physical fitness that has to be sufficiently developed across the lifespan to successfully perform sport and everyday activities like walking. Especially level of 
lower extremity muscle strength is required for people's gait ability (Muehlbauer, Gollhofer \& Granacher, 2015). Trunk muscle strength and abdominal muscle strength are important for mobility. Decreased flexor and extensor trunk muscle strength, reduced spinal mobility, in such a case, cause low back pain and leg pain in people. Such pain reduces walking ability that is a daily function (Durmus, Durmaz \& Canturk, 2010).

Painful conditions of the back pain, leg pain cause some changes in walking. Lower velocity and shorter steps, shorter duration of the stance phase on the painful side is observed. Other changes in gait patterns can be induced by joint swelling and muscle weakness (Perry, 1992).

Depending on underlying causes can be difficult to determine the pain in the body caused by low force implementation apart from the sensitivity to pain. With pressure pain threshold

and sensitivity level monitoring, underlying problems, pain levels, improvement speed and level can be followed (Akyol, Arslan \& Çolak, 2016).

The six-minute walk test is routinely used to assess the functional walking ability of people and evaluate functional capacity in daily activities. The 6 six-minute walk test is used to measure the maximum distance that a person can walk in 6 minutes. The primary measurement is the total distance walked. Walk distance is effected from personal ability, physical position, and visual ability. The shorter the pace of walking in six minutes is because short people have shorter step lengths. Older and heavier subjects usually have reduced muscle mass and therefore, shorter 6 six minute walk test, as do those who are less motivated or have impaired cognition. Because of 6 six minute walk test is used to assess the functional walking ability of people, tests may be helpful to yield up people's pulmonary function, cardiac function, , muscle strength, visual ability and cognitive function (Enright., 2003; Reis, Gustavo, Costa, Schmidt, Ferreira\& Abreu1, 2012; Pradon, Roche, Enette \& Zory, 2013; Steffen, Hacker \& Mollinger , 2002).

For all these reasons, we want to assess the relation between walk distance and muscle strength, muscle pain with visually disabled people.

\section{Methods}

A total of 50 visually disabled people (30 males, 20 females; age 17,21 \pm 5,3.years, weight $53.73 \mathrm{~kg} \pm 11.12 \mathrm{~kg}$, height $1.62 \mathrm{~m} \pm 0.177 \mathrm{~m} \pm$ standard deviation) participated in this study. The International Blind Sports Association (ISBA) uses a three-class system to classify persons who are blind or visually impaired. All classifications are in the better eye with best correction. (ISBA handbook, 1993).B1: From no light perception at all in either eye up to and including the ability to perceive light, with the inability to recognize objects or contours in any direction and at any distance. B2: Ability to recognize objects or contours up to a distance of 2 meters that a person with normal vision can see at 60 meters (i.e. below 2/60 vision) and/or field of vision less than 5 degrees B3: Can recognize objects or contours between 2 and 6 meters away that a person with nonnal vision can see at 60 meters (i.e. 2/60 to 6160 vision) and/or field of vision between 5 and 20 degrees (Tepfer\& Amanda, 2004).

\subsection{Six Minute Walk Test (6MWT)}

Each subject was instructed to walk as far as possible in 6 min (six minute walk test distance), at their own speed (Muehlbauer, Gollhofer \& Granacher, 2015). Subjects walked lengths of a 30-m walking track marked by a cone at each end, which they were instructed to walk around. The total distance covered in meters during the 6 min of walking was used as the score for each session (Durmus, Durmaz \& Canturk, 2010).

\subsection{Muscle Test}

As part of the muscle test, we evaluated hip flexör muscles, hip extension muscles back extensors, abdominal muscles and anterior trunk flexors. Muscle testing was conducted according to Dr. Robert W. Lovett's (Otman, Demirel \&Sade, 1998) manual muscle testing method. This test comprises the following categories: Normal (5): muscle completes the range of motion with maximum resistance against gravity. Good (4): muscle completes its normal range of motion with resistance less than maximum resistance against gravity. Fair (3): muscle completes its normal range of motion against gravity. Poor (2): muscle completes its normal range of motion in a position with gravity eliminated. Trace (1): palpable contraction before disclosure of motion in the joint. Total paralysis (0): No muscle contraction is felt.

\subsection{Pain Threshold}

Pain threshold in the quadriceps femoris, hamstring and tibialis anterior muscles were determined with J-Tech digital algometer (J-Tech Medical Industries Algometer Commander). The applied force used for the calibration of the device was set to Newton $(\mathrm{N})$. Each time the device is turned on, it automatically self-calibrates displaying zero. The measurement of muscle pain threshold were measured with the $1 \mathrm{~cm}^{2}$ probe tip.

Measurements were repeated three times at 5-second intervals and the average values were recorded. Each evaluation was applied in relaxation position. The participants were asked to say "Yes" each time they felt pain in each contact. 
Each time the patients said "Yes," the device was held back for 5 seconds to provide relief; the second and third measurements from the same spot were then carried out after the relaxation period (Lydia, Roberto \& Fil 2012; Özer, 2002). Pain threshold measurements were recorded twice for each participant for each region.

\section{Results}

Power analysis suggested at least 10 individuals in each group with the ... difference of the groups of 8.57 , standard deviation of 5.5, type I error of 0.05 and type II error of 0.20 (Hintze, 2011). The data were expressed as either median (min-max) values or mean (standard deviation, SD) depending upon overall variable distribution. Normality was assessed using Shapiro Wilk test. The normally distributed data were analyzed by one-way ANOVA followed by Bonferroni or Tamhane T2 post-hoc test. Correlations were estimated using Pearson correlation coefficient as appropriate. $\mathrm{P}<0.05$ values were considered as significant. IBM SPSS statistics version 23.0 for Windows was used for statistical analyses.

Table 1. Demographic characteristics of groups

\begin{tabular}{llllll}
\hline Variable & $\mathrm{n}$ & $\min$ & $\max$ & Mean & Std. Deviation \\
\hline Age(year) & 50 & 7.00 & 23.00 & 17.21 & 5.3 \\
Weight $(\mathrm{kg})$ & 50 & 22 & 84 & 53.73 & 11.12 \\
BMI $\left(\mathrm{kg} / \mathrm{boy}^{2}\right)$ & 50 & 17.60 & 47.10 & 30.63 & 6.32 \\
Height $(\mathrm{cm})$ & 50 & 1.10 & 1.86 & 1.56 & 0.16 \\
\hline
\end{tabular}

Table 2. Mean and standard deviation of age variable for each groups

\begin{tabular}{l|l|l|l}
\hline \multirow{2}{*}{ Variable } & Group & \multicolumn{3}{|l}{} \\
\cline { 2 - 4 } & $\begin{array}{l}\text { B1 } \\
(n=11)\end{array}$ & $\begin{array}{l}\text { B2 } \\
(n=19)\end{array}$ & $\begin{array}{l}\text { B3 } \\
(n=20)\end{array}$ \\
\hline Age $($ mean \pm SD) & $18.24(3.51)$ & $16.31(4.07)$ & $15.12(4.14)$ \\
\hline
\end{tabular}

Table 3. Correlations of walk distance and muscles

\begin{tabular}{|c|c|c|c|c|c|c|c|c|c|}
\hline & $\begin{array}{l}\text { Visual } \\
\text { Degree }\end{array}$ & $\begin{array}{l}\text { Back } \\
\text { extansions }\end{array}$ & $\begin{array}{l}\text { Lateral } \\
\text { trunk } \\
\text { flexors }\end{array}$ & $\begin{array}{l}\text { Anterior } \\
\text { Trunk } \\
\text { flexors }\end{array}$ & $\begin{array}{l}\text { Lower } \\
\text { abdominal } \\
\text { obliqs }\end{array}$ & $\begin{array}{l}\text { Hip } \\
\text { flexors }\end{array}$ & $\begin{array}{l}\text { Hip } \\
\text { extansions }\end{array}$ & $\begin{array}{l}\text { Hip } \\
\text { abductions }\end{array}$ & $\begin{array}{l}\text { Knee } \\
\text { extansion }\end{array}$ \\
\hline $\begin{array}{l}\text { Walk } \\
\text { distance }\end{array}$ & B1 & $\begin{array}{l}\mathrm{r}=0.244 \\
\mathrm{p}=0.446\end{array}$ & $\begin{array}{l}\mathrm{r}=0.060 \\
\mathrm{p}=0.853\end{array}$ & $\begin{array}{l}\mathrm{r}=0.127 \\
\mathrm{p}=0.694\end{array}$ & $\begin{array}{l}\mathrm{r}=0.470 \\
\mathrm{p}=0.123\end{array}$ & $\begin{array}{l}\mathrm{r}=0.095 \\
\mathrm{p}=0.769\end{array}$ & $\begin{array}{l}r=0.095 \\
p=0.769\end{array}$ & $\begin{array}{l}\mathrm{r}=0.095 \\
\mathrm{p}=0.769\end{array}$ & $\begin{array}{l}\mathrm{r}=-0.064 \\
\mathrm{p}=0.842\end{array}$ \\
\hline $\begin{array}{l}\text { Walk } \\
\text { distance }\end{array}$ & B2 & $\begin{array}{l}r=0.259 \\
p=0.257\end{array}$ & $\begin{array}{l}r=0.466^{*} \\
\mathrm{p}=0.033\end{array}$ & $\begin{array}{l}r=0.398 \\
p=0.074\end{array}$ & $\begin{array}{l}r=0.533 \\
p=0.013\end{array}$ & $\begin{array}{l}\mathrm{r}= \\
0.560 * * \\
\mathrm{p}=0.008\end{array}$ & $\begin{array}{l}\mathrm{r}=0.571 * * \\
\mathrm{p}=0.002\end{array}$ & $\begin{array}{l}\mathrm{r}=0.470^{*} \\
\mathrm{p}=0.032\end{array}$ & $\begin{array}{l}\mathrm{r}=0.496^{*} \\
\mathrm{p}=0.022\end{array}$ \\
\hline $\begin{array}{l}\text { Walk } \\
\text { distance }\end{array}$ & B3 & $\begin{array}{l}r=0.391 \\
p=0.053\end{array}$ & $\begin{array}{l}r=0.456^{*} \\
p=0.022\end{array}$ & $\begin{array}{l}\mathrm{r}=0.490^{*} \\
\mathrm{p}=0.013\end{array}$ & $\begin{array}{l}r=0.659 * * \\
p=0.000\end{array}$ & $\begin{array}{l}r=0.348 \\
p=0.088\end{array}$ & $\begin{array}{l}\mathrm{r}=0.348 \\
\mathrm{p}=0.088\end{array}$ & $\begin{array}{l}\mathrm{r}=0.255 \\
\mathrm{p}=0.219\end{array}$ & $\begin{array}{l}\mathrm{r}=0.396^{*} \\
\mathrm{p}=0.050\end{array}$ \\
\hline
\end{tabular}

In $\mathrm{B} 2$ group there was significant moderate correlation between walk distance and hip flexor muscles (Pearson correlation $=0.560 ; \mathrm{p}=0,008)$.

In B2 group there was significant moderate correlation between walk distance and lower abdominal muscles (Pearson correlation $=0.533 ; \mathrm{p}=0,013)$.

In $\mathrm{B} 2$ group there was significant moderate correlation between walk distance and hip extension muscles (Pearson correlation $=0.571 ; \mathrm{p}=0,002)$.

In B3 group there was significant moderate correlation between walk distance and anterior trunk flexor muscles (Pearson correlation $=0.490 ; \mathrm{p}=0,013$ ).

In B3 group there was nearly significant high correlation between walk distance and lower abdominal oblique muscles (Pearson correlation $=0.659 ; \mathrm{p}<0,001)$.

Table 4. Mean and standard deviation of pain threshold muscles and walk distance for each groups

\begin{tabular}{|c|c|c|c|c|c|c|c|}
\hline \multirow[b]{3}{*}{ Variables } & \multicolumn{6}{|l|}{ Group } & \\
\hline & \multicolumn{2}{|c|}{$\mathrm{B} 1(\mathrm{n}=11)$} & \multicolumn{2}{|c|}{ B2 $(n=19)$} & \multicolumn{2}{|c|}{ B3 $(n=20)$} & \\
\hline & Mean & Standard Deviation & Mean & Standard Deviation & Mean & Standard Deviation & $P$ \\
\hline Walk distance & 513,33 & 90,79 & 600,00 & 163,62 & 605,20 & 175,29 & 0,223 \\
\hline Pain threshold of quadriceps & $18,45^{*} \#$ & 4,19 & 23,62 & 4,56 & 27,02 & 6,96 & $<0,001$ \\
\hline Pain threshold of hamstring & $16,26 \#$ & 4,27 & 21,05 & 4,49 & 24,94 & 7,03 & $<0,001$ \\
\hline Pain threshold of tibialis anterior & 12,91\# & 3,71 & $16,68 \#$ & 4,95 & 20,62 & 6,30 & $\langle 0,001$ \\
\hline
\end{tabular}

*: significantly different from B2; \#: significantly different from B3; 
There were significant differences in pain threshold of quadriceps, pain threshold of hamstring and pain threshold of tibialis anterior among the groups. In relation to pain threshold of quadriceps, the mean of B1 was significantly different from B2 and B3 ( $<<0,05)$; whereas the mean of B2 was not significantly different from B3 $(p>0,05)$. For pain threshold of hamstring, the mean of the B1 was significantly different from B3 $(p<0,05)$. The B3 mean of pain threshold of tibialis anterior was significantly different from B1 and B2 $(\mathrm{p}<0,05)$.

Table 5. Relationship between walking distance and muscle strength according to visual degree

\begin{tabular}{l|l|l|l|l}
\hline & $\begin{array}{l}\text { Visual } \\
\text { Degree }\end{array}$ & Quadriceps femoris & Hamstring & Tibialis anterior \\
\hline Walk distance & $\mathrm{B} 1$ & $\begin{array}{l}\mathrm{r}=-0.078 \\
\mathrm{p}=0.81\end{array}$ & $\begin{array}{l}\mathrm{r}=0.243 \\
\mathrm{p}=0.447\end{array}$ & $\mathrm{r}=-0.338$ \\
& & $\mathrm{p}=0.282$ \\
\hline Walk distance & $\mathrm{B} 2$ & $\mathrm{r}=0.326$ & $\mathrm{r}=0.394$ & $\mathrm{r}=0.348$ \\
& & $\mathrm{p}=0.149$ & $\mathrm{p}=0.077$ & $\mathrm{p}=0.123$ \\
\hline Walk distance & $\mathrm{B} 3$ & $\mathrm{r}=0.645$ & $\mathrm{r}=0,605$ & $\mathrm{r}=0.598$ \\
& & $\mathrm{p}=0.001$ & $\mathrm{p}=0.001$ & $\mathrm{p}=0.002$ \\
\hline
\end{tabular}

There were positive relationships between walking distance and quadriceps femoris, hamstring and tibialis anterior.

In B2 group there was significant moderate correlation between walk distance and hip flexor muscles, lower abdominal muscles and hip extension muscles.

In B3 group there was significant moderate correlation between walk distance and anterior trunk flexor muscles and there was nearly significant high correlation between walk distance and lower abdominal oblique muscles.

There were significant differences in pain threshold of quadriceps, pain threshold of hamstring and pain threshold of tibialis anterior among the groups. In relation to pain threshold of quadriceps, the mean of B1 was significantly different from B2 and B3, whereas the mean of B2 was not significantly different from B3. For pain threshold of hamstring, the mean of B1 was significantly different from B3. B3 mean of pain threshold of tibialis anterior was significantly different from $\mathrm{B} 1$ and $\mathrm{B} 2$.

When people move, visual area is important. If the visual area is wide people can move smoothly and safely. When we walk we use our visual input and muscles. For a full gait, coordination must be between muscles and visual input. Visual impairment, decreased muscle strength and pain on the muscles affect walking in the negative direction. Visually disabled people have partial visual area on eyes and they worry to fall down while walking.

Just because of this they walk slowly and they cannot take long distance when they walk. If people have pain on muscle they don't want to carry on walk. Because walking is limited by pain. In addition to visual impairment, muscle strength and muscle pain problems can effect walking and walk distance on people who have visual impairment.

For all these reasons, if we want to develop walking ability which is a part of life in visual people, firstly we should consider exercise programme according to muscle groups that are effective in walking and that are less painful. When we develop muscles strength and decrease muscles pain, these people can walk in safety and they can take long distance without falling down in daily life. So that we can make these people more independent in their daily lives and give them community.

\section{Discussion}

The aim of this study was to determine, in visually disabled people whether or not muscle strength and muscle pain threshold were related to 6MWT (six minute walk test) performance. The results of this study since 6MWT performance was significantly correlated with the muscle strength because in B2 group there is significant moderate correlation between walk distance and hip flexor muscles, lower abdominal muscles, hip extension muscles. In B3 group there is significant moderate correlation between walk distance and anterior trunk flexor muscles and there is nearly significant high correlation between walk distance and lower abdominal oblique muscles. Muscles strengthening improve performance of walking (Chetta , Zanini , Pisi , Aiello, Tzani \& Neri, 2006). Camarri et al. suggests that health problems and plantar flexor strength have a great influence on six minute walk distance (Chetta, Zanini, Pisi, Aiello, Tzani \& Neri, 2006).

Landers et al. cited that the reduction in leg muscles strength is one of the causes of poor performance in activities such as walking, sitting/standing, which in turn may interfere with the performance in the walk test (Landers, Hunter, Wetzstein, Bamman \& Weinsier, 2001).

Hip abductor muscle weakness results in impaired pelvic control during gait. Muscles in a fatigued state may behave like weak muscles as they experience a reduced ability to produce force. Reduction in force production, either from weak or fatigued muscles, limits the body's ability to attenuate the high forces associated with dynamic movements (Singha, Pattnaikb , Mohantyb \& Ganeshb, 2016). It can be thought that muscle strength can affect walking ability. 
While walking lower extremity muscles, hip muscles are active and these muscles facilitate to stay on balance. So people can walk long distance without falling down. Shreya et al. showed that hip abductor muscle strengthening can reduce knee load and improve pain and physical function in people (Singha, Pattnaikb, Mohantyb \& Ganeshb, 2016).

In this study, it is seen that there is significant correlation between walk distance and hip flexor muscles, lower abdominal muscles, hip extension muscles, lower abdominal oblique muscles. Based on this context, a muscle strengthening protocol may improve performance in the 6MWT, thus increasing the distance walked (Reis, Gustavo, Costa, Schmidt, Ferreira\& Abreu1, 2012).

The aging process promotes a gradual decrease in both muscle mass and muscle strength, with an estimated 5\% loss in muscle mass every decade after age 40 affecting mainly the lower limbs (Reis, Gustavo, Costa, Schmidt, Ferreira\& Abreu1, 2012).

This study's average age is $14,31 \pm 4,1$. This is an advantage in this study because there is no muscle mass problem in people who are participate in the study.

As the visual capacity increases, the walking distance of people seems to increase. When visual people are classified into their visually degree there was seen that the muscles that related to walk distance were different from each other. In order that visual area is important for visually impaired people who worry to fall down while walking. Just because of this they walk slowly and they can't take long distance when they walk.

For a people with visual sensory disabilities, the most difficulty is to give to his gesture an expendable space through a different motory idea. It is important that those people listen to the changes of the motory inputs, using useful stimuli which promote his learning and his discovery of the space around (Bellomo, Barassp, Pancrazio \& Sagginp, 2012). They learn, with different times and rates, to use the surrounding space and its different forms and can relate to it with the help and the voice of other people around (Eimer, 2004; Rösler \& Bötting, 2004).

Bellomo et al. indicated that if balance and muscle control can be increased in visually sensory disabled people, it would be good improvement of the painful-dysfunctional situation, improvement of the quality of life in the subjects. They indicated that it resulted effectively in improving posture and balance in all patients with increased precision in the execution of the step, which implies less effort during walk, less energy consumption and better quality of life (Bellomo, Barassp, Pancrazio \& Sagginp, 2012).

Our study also showed a relationship between muscular strength, muscle pain and walk distance in visually disabled individuals. As muscle pain decreased and muscle strength increased, there was an increase in walking distance. We observed that the differences in walking distance values in our study constituted the visually disabled degree of the participants. As the area of vision expands, the balance and motor control increase during walking.

If we want to develop walk distance in visually disabled people firstly we should consider which muscle groups are important to walk, balance. We must plan exercise programme to according these muscles. When we develop muscles force and reduce muscle pain, these people can walk in safety and they can take long distance without falling down. So that we can make these people more independent in their daily lives and give them community.

\section{References}

Akyol, B., Arslan, C., \& Çolak, C. (2016). The effect of callisthenic exercises on pain threshold, pain severity and muscle strength on sedentary women diagnosed with upper extremity and low back pain. Journal of Turgut Ozal Medical Center, 23(1), 29-35. https://doi.org/10.5455/jtomc.2015.2954

Beauchet, O., Launay, C. P., Fantino, B., Allali, G., \& Annweiler, C. (2015). Respective and combined effects of impairments in sensorimotor systems and cognition on gait performance: a population-based cross-sectional study. PloS one, 10(5), e0125102. https://doi.org/10.1371/journal.pone.0125102

Bellomo, R. G., Barassp, G., Iodice, L., Di Pancrazio, P., Megna, A. R., \& Sagginp, M. (2012). Visual Sensory Disability: Rehabilitative Treatment In An Aquatic Environment. International Journal of Immunopathology and Pharmacology, 25(1), 17-22. https://doi.org/10.1177/03946320120250S103

Chetta, A., Zanini, A., Pisi, G., Aiello, M., Tzani, P., Neri, M., \& Olivieri, D. (2006). Reference values for the 6-min walk test in healthy subjects 20-50 years old. Respiratory medicine, 100(9), 1573-1578. https://doi.org/10.1016/j.rmed.2006.01.001

Durmus, D., Durmaz, Y., \& Canturk, F. (2010). Effects of therapeutic ultrasound and electrical stimulation program on pain, trunk muscle strength, disability, walking performance, quality of life, and depression in patients with low back pain: a randomized-controlled trial. Rheumatology International, 30(7), 901-910.

https://doi.org/10.1007/s00296-009-1072-7 
Eimer, M. (2004). Multisensory integration: how visual experience shapes spatial perception. Current Biology, 14(3), R115-R117. https://doi.org/10.1016/j.cub.2004.01.018

Enright, P. L. (2003). The six-minute walk test. Respiratory Care, 48(8), 783-785.

Hallemans, A., Ortibus, E., Meire, F., \& Aerts, P. (2010). Low vision affects dynamic stability of gait. Gait \& posture, 32(4), 547-551. https://doi.org/10.1016/j.gaitpost.2010.07.018

Hintze, (2011). PASS 11. NCSS, LLC. Kaysville, Utah, USA. www.ncss.com.

Hötting, K., Rösler, F., \& Röder, B. (2004). Altered auditory-tactile interactions in congenitally blind humans: an event-related potential study. Experimental Brain $\quad$ Research, 159(3), 370-381. https://doi.org/10.1007/s00221-004-1965-3

Landers, K. A., Hunter, G. R., Wetzstein, C. J., Bamman, M. M., \& Weinsier, R. L. (2001). The interrelationship among muscle mass, strength, and the ability to perform physical tasks of daily living in younger and older women. The Journals of Gerontology Series A: Biological Sciences and Medical Sciences, 56(10), 443-448. https://doi.org/10.1093/gerona/56.10.B443

Muehlbauer, T., Gollhofer, A., \& Granacher, U. (2015). Associations between measures of balance and lower-extremity muscle strength/power in healthy individuals across the lifespan: a systematic review and meta-analysis. Sports medicine, 45(12), 1671-1692. https://doi.org/10.1007/s40279-015-0390-z

Nakamura, T. (1997). Quantitative analysis of gait in the visually impaired. Disability and Rehabilitation, 19(5), 194-197. https://doi.org/10.3109/09638289709166526

Otman, S. A., Demirel, H., \& Sade, A. (1998). Tedavi Hareketlerinde Temel Değerlendirme Prensipleri. Ankara. Hacettepe Üniversitesi Fizik Tedavi ve Rehabilitasyon Yaylnları 16, 2. Baskl.

Özer D. (2002). Temporomandibular eklem disfonksiyonsendromunda rol oynayan etyolojik faktorlerin ve semptomların araşttrılması. (Yüksek lisans tezi). Hacettepe Universitesi/Sağlık Bilimleri Enstitüsü, Ankara.

Perry, J., \& Davids, J. R. (1992). Gait analysis: normal and pathological function. Journal of Pediatric Orthopaedics, 12(6), 815. https://doi.org/10.1097/01241398-199211000-00023

Pradon, D., Roche, N., Enette, L., \& Zory, R. (2013). Relationship between lower limb muscle strength and 6-minute walk test performance in stroke patients. Journal of Rehabilitation Medicine, 45(1), 105-108. https://doi.org/10.2340/16501977-1059

Reis, J. G., Costa, G. C., Schmidt, A., Ferreira, C. H., \& Abreu, D. C. (2012). Do muscle strengthening exercises improve performance in the 6-minute walk test in postmenopausal women?. Brazilian Journal of Physical Therapy, 16(3), 236-240. https://doi.org/10.1590/S1413-35552012005000022

Singh, S., Pattnaik, M., Mohanty, P., \& Ganesh, G. S. (2016). Effectiveness of hip abductor strengthening on health status, strength, endurance and six minute walk test in participants with medial compartment symptomatic knee osteoarthritis. Journal of Back and Musculoskeletal Rehabilitation, 29(1), 65-75. https://doi.org/10.3233/BMR-150599

Steffen, T. M., Hacker, T. A., \& Mollinger, L. (2002). Age- and gender-related test performance in community-dwelling elderly people: six-minute walk test, berg balance scale, timed up \& go test, and gait speeds, Phys. Ther. Feb, 82(2), 128-137. https://doi.org/10.1093/ptj/82.2.128

Tepfer, A. (2004). The Socialization of Elite Blind Athletes into Sport Kinesiology, Sport Studies, and Physical Education Master's Theses. 9. Brockport, New York.

The International Blind Sports Association (ISBA). 1993, Ch. 4, p. 1.

Vela, L., Cano-de-la-Cuerda, R., Fil, A., Muñoz-Hellín, E., Ortíz-Gutiérrez, R., Macías-Macías, Y., \& Fernández-de-las-Peñas, C. (2012). Thermal and mechanical pain thresholds in patients with fluctuating Parkinson's disease. Parkinsonism \& Related Disorders, 18(8), 953-957.

https://doi.org/10.1016/j.parkreldis.2012.04.031

\section{Copyrights}

Copyright for this article is retained by the author(s), with first publication rights granted to the journal.

This is an open-access article distributed under the terms and conditions of the Creative Commons Attribution license which permits unrestricted use, distribution, and reproduction in any medium, provided the original work is properly cited. 